\title{
A SUSTENTABILIDADE URBANA ENTRA EM CENA
}

\section{URBAN SUSTAINABILITY COMES INTO THE SCENE}

\section{A. Leticia Barroso \& B. Vera L. Ferreira Rezende}

\author{
Universidade Federal Fluminense, Brasil \\ leticiabarroso@gmail.com \\ vrezende1234@gmail.com
}

\begin{abstract}
RESUMO
Nosso olhar se orienta para a construção da Cidade Sustentável, apontando para visões que buscam uma cidade real mais justa, o objetivo final e ideal das ações de urbanismo. Nossa abordagem considera que a sustentabilidade da cidade deve se ater a dois importantes elementos: a justiça ambiental e a resiliência. Destacamos seis propostas que se apresentam como "modelos de cidades" para refletir sobre a inserção da sustentabilidade, oito atributos foram definidos para a análise, que permitem estabelecer o grau de intensidade e comprometimento de cada um deles em cada uma das propostas de cidades anunciadas. Essa conjunção de pontuação resulta na construção da matriz "A Sustentabilidade nos modelos de cidades". Em nossa abordagem, consideramos a Cidade Sustentável aquela capaz de responder às adversidades, reduzir a desigualdade social, promover um ambiente seguro, mais adensado e com outros estilos de vida e a construir pactos para enfrentar os desafios. Mas, o desafio, o fio condutor, está na integração entre as políticas ambientais, urbanas, sociais e econômicas, ou seja, faz-se necessário integrar políticas com foco na sustentabilidade e em prioridades que contemplem a qualidade de vida da sociedade.
\end{abstract}

Palavras chave - sustentabilidade urbana, cidades, vulnerabilidade, justiça ambiental Linha de Investigação: 2: Cidade e Ambiente.

Tópico: Risco, vulnerabilidade e resiliência

\section{ABSTRACT}

Our gaze is oriented towards the construction of the Sustainable City, pointing to visions that seek a fairer real city, the final and ideal objective of urban planning actions. Our approach considers that 


\section{SÃOPAULO15 $\sim 17 \cdot$ LISBOA $25 \sim 26$ JUN 2020}

the sustainability of the city must stick to two important elements: environmental justice and resilience. We highlight six proposals that are presented as "city models" to reflect on the insertion of sustainability, eight attributes were defined for the analysis, which allow to establish the degree of intensity and commitment of each one of them in each of the announced city proposals. This conjunction of scoring results in the construction of the matrix "Sustainability in city models". In our approach, we consider the Sustainable City to be capable of responding to adversities, reducing social inequality, promoting a safer, denser environment with other lifestyles and building pacts to face challenges. However, the challenge, the guiding thread, lies in the integration between environmental, urban, social and economic policies, that is, it is necessary to integrate policies with a focus on sustainability and priorities that contemplate the quality of life of society.

Keywords - urban sustainability, cities, vulnerability, environmental justi

Research line: 2: City and Environment.

Topic: Risk, vulnerability and resilience

\section{Introdução}

Estamos assistindo nas últimas décadas novas formas de ver a cidade. Mas nosso olhar será para a construção da Cidade Sustentável, que requer novas visões capazes de orientar a possível cidade mais justa, que deveria ser o objetivo final das ações de urbanismo. Nesse sentido, buscamos neste trabalho iluminar nosso entendimento sobre as diversas dimensões urbanas que de fato vem contribuindo para a cidade sustentável. E repensar o posicionamento do urbanismo e de uma política de cidades.

Pensar cidades sustentáveis implica não só inserir questões ambientais, mas também incorporar as dimensões sociais, econômicas e culturais que vêm se consolidando por meio de princípios, métodos e ações.

Projetos, programas e ações vêm sendo pensados, debatidos por institutos de pesquisa, universidades e órgãos governamentais do meio ambiente, na tentativa de reverter o quadro atual das cidades a partir de um alinhamento com as propostas acordadas nos tratados internacionais. Farias (2015, p.11) afirma que:

A construção da cidade sustentável é um projeto complexo que se alcança através de uma estreita colaboração entre a administração pública e os centros de pesquisa, além de dispor de processos de monitoramento e avaliação sistemáticos. Mesmo em nossas grandes cidades, as pesquisas urbanísticas aplicadas ainda são incipientes, generalistas ou descontínuas. Não raro, adotamse soluções tecnológicas incertas, pois não se avaliam com precisão questões como adequação, mitigação ou resiliência. 


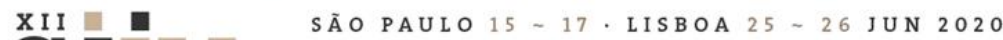

Consideramos que, para buscar a sustentabilidade da cidade, deve-se ater a dois importantes elementos: a justiça ambiental e a resiliência. O primeiro remete à reflexão sobre a apropriação dos recursos ambientais e o modo de organização do espaço, na produção e reprodução da sociedade. Já a Resiliência introduz uma nova abordagem para se lidar com a gestão das cidades e a fim de mantê-las em um estado contrário ao da vulnerabilidade. Isso significa desenvolver capacidades adaptativas das cidades a eventos adversos e a ameaças naturais.

Tornar-se resiliente impõe conhecer, com profundidade, a dimensão dos riscos, as vulnerabilidades dos sistemas e promover a gestão dos possíveis desastres. Apesar de caminhar para o entendimento da Cidade Sustentável, tarefa que julgo difícil, vale anunciar que não se trata de um corolário para se chegar a uma cidade sustentável e nem de acreditar que as mudanças societárias se darão por conta de um planejamento urbano. Trata-se, sim, da construção de um novo olhar do espaço urbano, de um conjunto de práticas, instrumentos e mecanismos que possam garantir, de forma contínua e consciente, respostas aos desafios constantes e complexos, mediante a apropriação da cidade pelo conjunto da sociedade.

\section{Alinhavando a discussão da sustentabilidade e as formas de cidade}

Em todos os períodos da história, diversas abordagens e distintas formas urbanas anunciaram uma cidade boa de se viver. Repensar as cidades existentes implica admitir um presente caótico, que deve ser realizado um contraponto entre o mundo perfeito e a realidade imperfeita, ou seja, buscar a sustentabilidade das cidades

Mas o que se constata é que a noção de sustentabilidade pulverizou-se, dando lugar para outras abordagens, o que dificultou uma convergência teórica. Assim, o que se observa é que a sustentabilidade se insere em propostas de cidade, e passa a atuar ao lado de um conjunto de princípios, sendo, pois, uma das dimensões consideradas. Isso posto, destacamos seis propostas que se apresentam como "modelos/propostas de cidades", por conterem propósitos de melhorar a vida urbana: o Novo Urbanismo, a Cidade Compacta, a Cidade Inteligente, a Cidade Resiliente, a Cidade Biofílica e as Slow Cities. Trata-se de propostas que, além de responder ao momento de crise das cidades, com questões diferenciadas, também contribuem para o debate sobre a sustentabilidade urbana.

Em 1996, nos Estados Unidos, foi lançado o Novo Urbanismo. Ele foi baseado em 27 princípios presentes na "Carta do Novo Urbanismo", constituída de propostas alternativas ao modelo de 


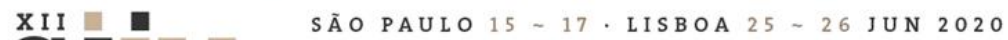

suburbanização a fim de evitar a ocupação dispersa. O Novo Urbanismo ${ }^{1}$ foi lançado como uma reação ao espraiamento das cidades, termo advindo do inglês "Spraw", tendo como uma das referências projetuais os Garden Cities $^{2}$. Andres Duany e Elizabeth Plater Zybert ${ }^{3}$ foram os maiores promotores do Novo Urbanismo.

Mas é no final do século XX, quando se intensificam os processos de urbanização, que os debates sobre as cidades contidas e as cidades espraiadas se ampliam: por um lado, o paradigma da cidade dispersa; por outro, a cidade compacta.

Diante dessa perspectiva, frente à intensidade da extensão de urbanização e dos impactos no âmbito ambiental e social, a cidade compacta tem sido apresentada como aquela capaz de responder a esses desafios por conter um conjunto de estratégias de intensificação do uso da cidade existente.

O discurso da Cidade Compacta constituiu-se, no século $\mathrm{XX}$, em um momento de intensa urbanização, período em que diversos urbanistas declararam preocupações com a cidade. A Cidade Compacta discute a densidade e, consequentemente, a redução de deslocamentos, usos mistos nas cidades e, assim, a redução de custos e maior eficiência na utilização de energia. ${ }^{4}$

Jahn Geul (2014), Richard Rogers (2016)5, Marta Romero (2003) e Henri Acselrad (2001) apontam que a Cidade Compacta poderia orientar o crescimento urbano, pela possibilidade de se promover mais equidade, mais encontros nos espaços públicos respaldados por um conjunto de estratégias de intensificação do uso da cidade existente. Isso posto, as áreas de expansão deverão ser limitadas e deverá ocorrer a formação de novas centralidades.

\footnotetext{
1 Em outubro de 1993, foi realizado o I Congresso do Novo Urbanismo (I CNU), na cidade de Alexandria, estado da Virgínia, nos Estados Unidos, com a participação de 170 profissionais afinados com a temática do planejamento urbano. Em 1996, foi realizado o IV Congresso, IV CNU, em Charlestown, Carolina do Sul, e foi assinada a Carta do Novo Urbanismo por 266 participantes.

${ }^{2}$ Garden Cities constituídos por seis magníficos boulevares - cada um com $36 \mathrm{~m}$ de largura - cruzam desde o centro até a circunferência, transversalmente a cidade, dividindo-a em seis partes ou distritos iguais. No núcleo há um espaço circular de aproximadamente de 2,2ha, disposto como um belo e bem irrigado jardim e, ao seu redor, num amplo terreno próprio, estão os edifícios públicos - a sede da municipalidade, as principais salas para concertos e conferências, o teatro, a biblioteca, o museu, a galeria de arte e o hospital. (HOWARD.1996. p.115)

${ }^{3}$ Arquitetos que fundaram a empresa Plater-Zyberk \& Company (DPZ), na Florida, em 1980, especializados no Novo Urbanismo nos Estados Unidos e em outros países.

${ }^{4} \mathrm{O}$ artigo "Gasoline consumption in cities: a comparison of US cities with a globl survey", lançado em 1989, de Neuwman e Kenworthy, estabelece uma relação entre consumo de combustível e densidade urbana e aponta a cidade compacta com uma das formas urbanas que apresenta numerosos benefícios ambientais.

${ }^{5}$ Richard Rogers, em 1998, coordenou a Comissão Urban Task Force, na Inglaterra, que analisou os problemas das cidades inglesas e apontou paradigmas da cidade compacta.
} 


\section{SÃOPAULO15 $\sim 17 \cdot$ LISBOA $25 \sim 26$ JUN 2020}

Outra proposta é a Cidade Inteligente, Smart City, ${ }^{6}$ baseada no conhecimento avançado, que insere novas formas de tecnologia da informação e comunicação para garantir a melhoria da gestão da cidade. Trata-se de um conceito que emergiu na primeira década do século $X X$, com base em experiências desenvolvidas a partir da iniciativa privada.

As Cidades Inteligentes, segundo alguns autores, são aquelas que reconhecem a importância das Tecnologias de Informação e de Comunicação e que deveria contribuir para uma ação mais integradora de forma a envolver pessoas para a participação na construção de um ambiente melhor. Assim, a tecnologia poderia ser um elemento de conexão que possibilitaria a proposição de ações para a sustentabilidade da cidade.

No entanto, hoje, o que se percebe, é o uso da tecnologia apenas como instrumento, de forma que ele não auxilia na diminuição de problemas urbanos, como a exclusão social e a desigualdade espacial.

Outro conceito importante, o de Cidade Resiliente, surgiu por conta do crescente aumento de ocorrências de desastres naturais. Para enfrentamento desses problemas, a Organização das Nações Unidas - ONU -, desde 1960, vem desenvolvendo campanhas, programas e ações no sentido de prevenir, reduzir e recuperar os impactos nas cidades, tais como, enchentes, inundações, deslizamentos, entre outros.

Isso é um fato, mas pensar a Cidade Resiliente não é somente pensar estratégias para o enfrentamento de adversidades, mas também pensar na redução da pobreza.

Viver um outro estilo de vida urbana, que se contraponha ao acelerado ir e vir das pessoas na cidade contemporânea, é viver em uma cidade mais lenta, como preconizam as Slow Cities. Isso requer uma mudança de cultura e um novo olhar para a cidade. Para exemplificar, de 1960 a 1970, mais de oito mil novos shoppings foram inaugurados nos Estados Unidos. Surgiram, em 1999, na Itália, as Slow Cities, com vistas a proporcionar uma vida desacelerada, de forma que cada indivíduo possa apropriar-se do movimento das cidades e, assim, valorizar o uso dos parques, das praças, das áreas históricas. A própria cidade deve semear valores que a tornem mais lentas, de modo a melhorar a qualidade de vida dos cidadãos

Atualmente esse movimento está instalado em 30 cidades italianas e já se expandiu para Alemanha, Noruega, Reino Unido, Polônia, Portugal e Espanha. No Brasil, duas cidades - Antônio Prado (RS) e Tiradentes (MG) - já incluíram os princípios de Slow Cities.

\footnotetext{
${ }^{6}$ Outros conceitos análogos - Ubiquitous, Intelligent, Sustainable, Connected, Digital. Não há tradução literal
} para o termo "smart city" em português, que acabou sendo nomeado como "Cidade Inteligente". 


\section{SÃOPAULO $15 \sim 17 \cdot$ LISBOA $25 \sim 26$ JUN 2020

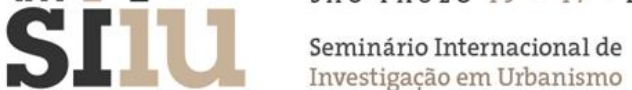 \\ Seminario Internacional de Investigación en Urbanismo}

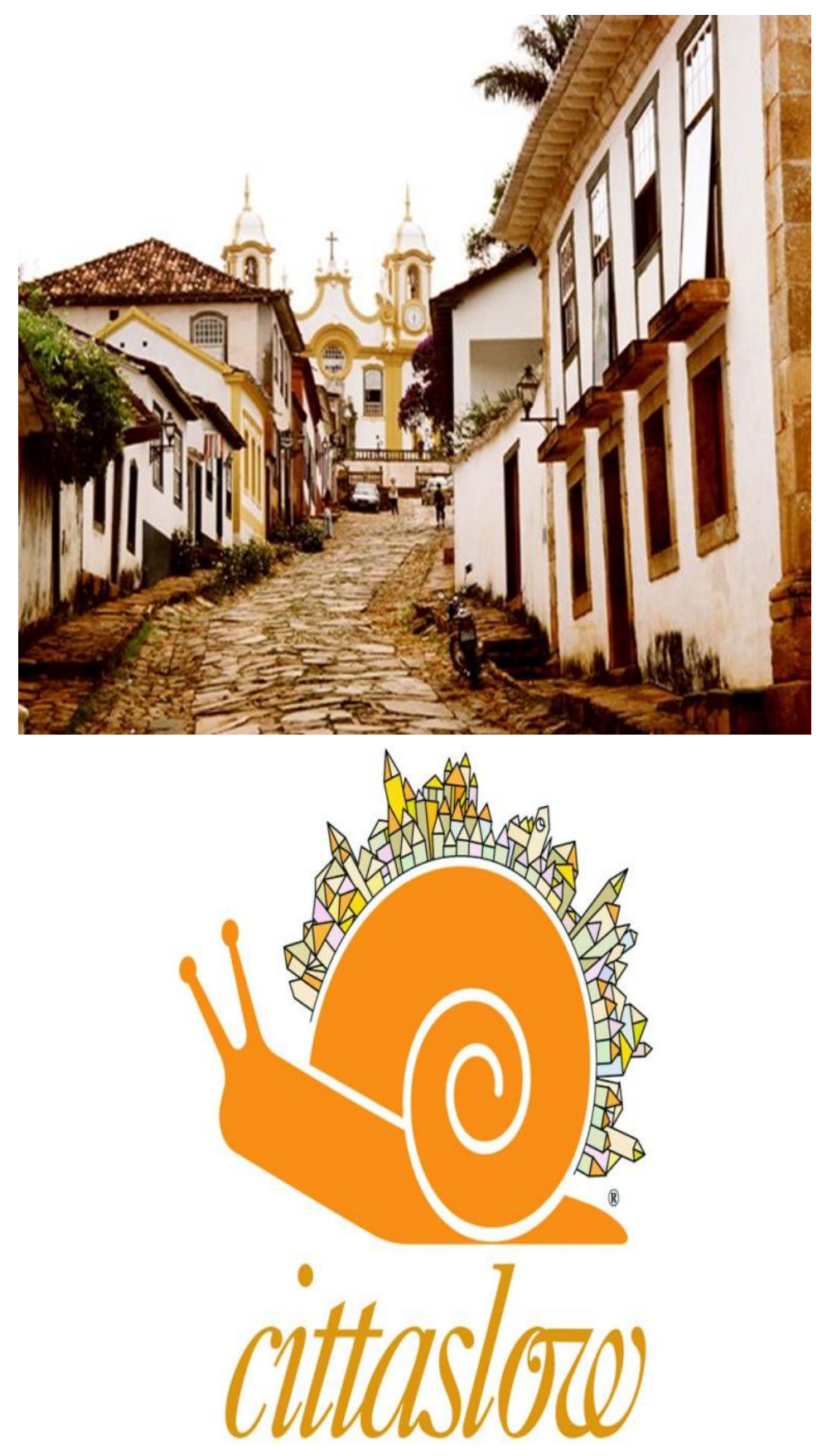




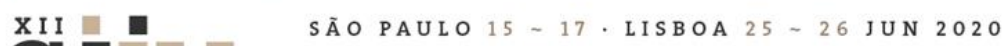

Fig. 1 - Cidade Brasileira - Slow Cities. Fonte:.https://www.google.com.br/\#q=cidade+de+Tiradentes

Para se tornar uma cidade "lenta" e ganhar o selo Slow City é necessário aplicar 55 princípios relacionados a política ambiental, sustentabilidade urbana, infraestrutura, incentivo à expansão de produtos locais e participação da comunidade.

Em 1984, Edward O. Wilson, em sua obra "Biophilia", apresentou a relação simbiótica entre o homem e a natureza, apontando a necessidade de todos experienciassem sentimentos de bemestar com a paisagem. Embasado nessas características, surgiu o conceito de Cidade Biofílica, as quais vem buscando a aproximação dos homens com a natureza. Para tanto, a criatividade entra em cena ao inserir espaços verdes em ruas, praças e edifícios.

As cidades que incorporam o pensamento da Cidade Biofílica carregam a preocupação com a preservação dos ecossistemas. 


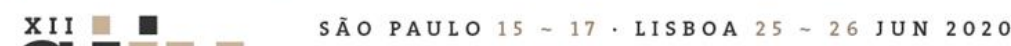

por meio dos infills, termo advindo do inglês, que se refere a preencher vazios frente ao espalhamento das cidades.

Há que se considerar que o aumento da compactação é, de certa forma, conflitante com o aumento de áreas verdes. Para minimizar esses problemas, uma proposta projetual e de planejamento deve contemplar estratégias de contenção, renovação e revitalização. Nesse sentido, a Cidade Compacta apoia-se numa modelização, ou seja, no modelo monocêntrico, que se revela em elementos de diversidade, acessibilidade e identidade.

A Cidade Inteligente não exige configuração espacial e sim um alinhamento de soluções tecnológicas às reais necessidades das pessoas. Quando se fala em Cidades Inteligentes, instaura-se um pensamento de cidades do futuro, com o aprimoramento da gestão aliado a um design inteligente.

Ainda na linha de refletir sobre a cidade, diversos discursos emergiram contra o modelo de cidades modernistas. Jan Gehl (2014) adverte, em seu livro "Cidades para as Pessoas", que as cidades deveriam oportunizar o convívio e ser pensadas ao nível dos olhos, ou seja, na escala humana. Nesse cenário, não cabem as grandes avenidas repletas de carros, que acabam empurrando a vida urbana para fora do espaço público.

Seria então o urbanismo a chave, o instrumento capaz de garantir o Direto a Cidade? Lefebvre declara que o urbanismo é incapaz de responder a essas questões, pois os urbanistas ignoram o espaço como produto das relações sociais, em que a máscara do Estado e da ação política são instrumentos de interesses dissimulados numa estratégia (Lefebvre, 2000). Assim, os urbanistas acabam modelando

O pensamento dos tecnocratas que oscila entre a representação de um espaço vazio, quase geométrico, tão-somente ocupado pelos conceitos, pelas lógicas e estratégias no nível racional mais elevado, e a representação de um espaço finalmente pleno, ocupado pelos resultados dessas lógicas e estratégias (LEFEBVRE, 2004, p. 141)

Além disso, ainda se verifica o "fato do urbanista pretender substituir e suplantar a prática urbana. Ele não a estuda. Para o urbanista, essa prática é, precisamente, um campo cego. E vive nele, nele se encontra, mas não o vê, e menos ainda o compreende como tal." (LEFEBVRE, 1999, p.141)

\section{Dimensões da cidade sustentável}

Para refletir sobre a inserção da sustentabilidade nos modelos apresentados e a contribuição para a cidade sustentável, oito dimensões foram definidas para nossa análise. Cada modelo conta, 


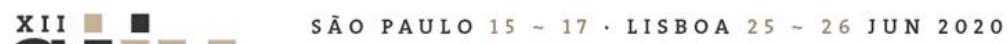

direta ou indiretamente, com uma ou mais dimensões, mas procuramos assinalar a que se destaca. Num primeiro momento, visamos compreender o objetivo principal da proposta de cidade, mas não ignoramos as relações existentes com as outras dimensões nem que a reflexão não se esgota neste momento.

Para a construção da matriz, busco referenciar alguns dos traços definidos por Choay (2010), em seu trabalho "A Regra e o modelo", para discriminar e identificar as utopias.

Choay considerou a obra de Thomas Morus um paradigma do gênero utopia e, a partir dela definiu elementos comuns para analisar outros textos e diferenciar os que se aproximam e aqueles que se afastam da Utopia. E, para discriminar utopias falsas das verdadeiras, a autora se apoia em sete traços. $^{7}$

Para tanto, transporto para a minha matriz dois traços estabelecidos por essa autora: 1- uma sociedade modelo opõe-se a uma sociedade histórica real, cuja crítica é indissociável da descrição-elaboração da primeira; 2 - a sociedade modelo tem como suporte um espaço - que é sua parte integrante e necessária. $\mathrm{E}$, a esses traços, acrescento outros: 3 - Tamanho; 4 Acessibilidade; 5 - Diversidade; 6 - Valorização da Economia Local; 7 - Espaços Verdes, 8 Tecnologia da Informação

Entende-se que a primeira questão, presente em todas as propostas, se refere à Participação. Não a colocamos na tabela por entender que seria o valor constante para todos, mas será considerada uma contribuição positiva. É fundamental conferir o poder político ao cidadão, de forma que os interesses possam ser colocados a partir do diálogo. É bem verdade que estamos assistindo, no Brasil, à pouca participação da população nos processos decisórios da cidade e que a sustentabilidade é apropriada como um discurso a ser utilizado para legitimar as ações públicas. Não podemos deixar de destacar que a sustentabilidade de uma cidade requer democracia e instrumentos necessários à sua consecução. Trouxemos a dimensão "tamanho da cidade" e a relação com a proposta da cidade, ou seja, buscamos identificar se há a preocupação com esse elemento no contexto da proposta/modelo. Além disso, consideramos importante avaliar duas questões: a primeira é identificar se a proposta requer uma crítica à sociedade existente e a outra é se há exigência de uma reestruturação espacial, uma forma espacial.

\footnotetext{
7 (1) Uma utopia é um livro assinado; (2) nela um indivíduo se exprime na primeira pessoa do singular, o próprio autor e/ou seu porta-voz, visitante ou testemunha da utopia; (3) apresenta-se sob uma forma de uma narrativa na qual se insere, no presente do indicativo, a descrição de uma sociedade-modelo; (4) uma sociedade modelo opõe-se a uma sociedade histórica real, cuja crítica é indissociável da descrição- da primeira; (5) a sociedade modelo tem como suporte um espaço - que é sua parte integrante e necessária; (6) a sociedade-modelo está situada fora do nosso sistema de coordenadas espaço-temporais, alhures; (7) ela escapa à influência do tempo e das mudanças. (CHOAY, 2010. p. 36-37)
} 


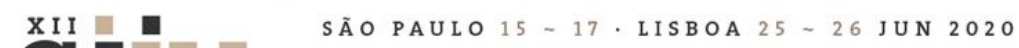

A "configuração espacial", no caso, significa ter como pauta uma forma geométrica do espaço e se refere a um desenho de uma cidade, de um bairro ou de uma região.

A seguir, consideramos a "acessibilidade", dimensão que está relacionada com o transporte, uma vez que verifica como se dá o uso coletivo de ciclovias e vias de pedestres - o que inclui a facilidade de acesso a um destino -, e está condicionada a uso do solo.

Quando se definiu a "diversidade" como uma das dimensões, apontamos para a variedade de usos mistos do solo numa determinada área. Isso quer dizer, por exemplo, que com menos uso de automóvel, as pessoas possam se encontrar mais e alcançar diferentes agrupamentos de atividades.

A dimensão "Tecnologia e a Informação" constituem-se de possibilidades de fornecer informações para a gestão do território com indicadores adequados para as tomadas de decisão e intervenção no urbano. Incluímos, também, a "Valorização da Economia Local". Dimensão que contempla se há investimentos em economias alternativas, baseando-se na autonomia dos atores locais. Tratase de um novo estilo de vida e de cultura. E, por último, analisamos a dimensão" Espaços Verdes", como elemento de oportunizar encontros e integração com a cidade.

A tabela a seguir, apresenta um resumo para identificar e pontuar os atributos contidos nas propostas, de forma a unir dimensões culminando em uma visão de cidade sustentável. Para compreender o desempenho das seis propostas da cidade, foi utilizado um método de pontuação simples, com critérios que podiam ser classificados como bom (+), indiferente (+/-) e ruim (-) onde (+) contribuiu muito positivamente e (-) não contribuiu. 


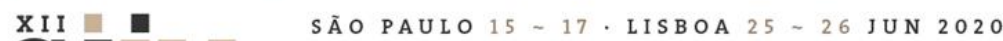 \\ Seminário Internacional de Investigação em Urbanismo \\ Seminario Internacional de Investigación en Urbanismo}

\begin{tabular}{|c|c|c|c|c|c|c|}
\hline Dimensões & $\begin{array}{c}\text { Novo } \\
\text { Urbanismo }\end{array}$ & $\begin{array}{c}\text { Cidade } \\
\text { Compacta }\end{array}$ & $\begin{array}{c}\text { Cidade } \\
\text { Inteligente }\end{array}$ & $\begin{array}{c}\text { Cidade } \\
\text { Resiliente }\end{array}$ & $\begin{array}{l}\text { Slow } \\
\text { Cities }\end{array}$ & $\begin{array}{l}\text { Cidade } \\
\text { Biofílica }\end{array}$ \\
\hline Tamanho da cidade & - & + & $+/-$ & $+/-$ & + & $+/-$ \\
\hline Crítica da sociedade & - & + & $+/-$ & + & + & $+/-$ \\
\hline Configuração espacial & + & + & $+/-$ & - & - & - \\
\hline Acessibilidade & + & + & $+/-$ & + & + & + \\
\hline Diversidade & + & + & $+/-$ & $+/-$ & + & $+/-$ \\
\hline Tecnologia/Informação & - & $+/-$ & + & + & - & - \\
\hline Economia Local & $+/-$ & $+/-$ & $+/-$ & $+/-$ & + & $+/-$ \\
\hline Espaços verdes & + & + & $+/-$ & + & + & + \\
\hline Pontuação & 1 & 6 & 1 & 3 & 4 & -1 \\
\hline
\end{tabular}

Tabela 1 - Sustentabilidade nos modelos de cidades Fonte: Elaborada pela autora. Leticia Barroso. 03/08/2017

Que aspectos seriam importantes para considerar uma cidade como sendo sustentável? Seriam as ferramentas tecnológicas suficientes para enfrentar os desafios? Seriam as Cidades Resilientes, com suas intervenções para prevenções e ajustes frente aos desastres naturais? Ou seriam as Cidades Compactas, com a possibilidade de redução de custos energéticos, aproximação entre as pessoas e acessibilidade satisfatória? Na tabela, consta a pontuação, de forma a responder ao grau de intensidade e comprometimento do atributo naquela proposta de cidade.

Ao olhar os resultados, na tentativa de identificar quais são os atributos que mais contribuem para uma cidade sustentável e apontar as forças existentes nas propostas de cidades, nota-se uma correlação. Num olhar mais apurado, identificamos que a Cidade Compacta e Slow City foram as mais pontuadas. Então, o mais valorizado foi a combinação de um espaço mais adensado e outros estilos de vida. Uma cidade mais lenta agrega valores de patrimônio histórico, de valorizar a economia local e de mais espaços públicos. O terceiro valor mais pontuado foi o referente à Cidade Resiliente.

Dessa forma, os elementos, atributos da Cidade Compacta, os da Slow City e os da Cidade Resiliente contribuem para a sustentabilidade da cidade, ou seja, a Cidade Sustentável seria uma cidade densa, mas lenta, com mecanismos e instrumentos que a tornassem, também, uma Cidade Resiliente.

É importante mencionar que a Cidade Resiliente é a única proposta que trata de ações de prevenções na cidade. Não é possível pensar em uma cidade sustentável se não pensar tanto na prevenção como na resiliência, uma vez que toda cidade convive com deslizamentos, inundações, enchentes. 


\section{SÃOPAULO15 $\sim 17 \cdot$ LISBOA $25 \sim 26$ JUN 2020}

Ao lado desses atributos, a Cidade Sustentável deverá contar com a tecnologia e informação. Trata-se da Cidade Inteligente, no sentido de apoiar gestão pública no que se refere aos espaços verdes, florestas, áreas permanentes, áreas de preservação ambiental e mobilidade urbana e de promover um diálogo com a resiliência da cidade, por meio de informações frente aos riscos naturais e socioambientais. A Cidade Inteligente busca garantir a gestão e a redução de custos da administração pública, mas fica a pergunta se este modelo poderá promover a redução da pobreza na cidade.

Para compor a cidade sustentável, são necessários, ainda, acessos mais fáceis e diversidade de usos, como propõe a Cidade Compacta, que propõe maior conectividade. É necessário, também, um olhar voltado para o fortalecimento da economia local - cuja valorização é pauta principal das Slow Cities, que visam à construção da identidade local e à preservação do patrimônio histórico.

Além disso, vale ressaltar a importância da adoção de áreas verdes para promover encontros entre as pessoas e a necessidade de equalizar a relação homem e natureza, como propõe a Cidade Biofílica, que promove a proteção e a construção de espaços verdes, com a perspectiva de integrar o homem e a natureza.

Nesse sentido, seria cuidadoso não tornar esses espaços espetacularizados e mercantilizados. Vêse, portanto, no breve exposto, que, embora seja possível relacionar os atributos, ainda há muito a ser estudado sobre a densidade ideal.

\section{Conclusão}

Em nossa abordagem, consideramos a Cidade Sustentável aquela capaz de responder às adversidades, reduzir a desigualdade social, promover um ambiente seguro, mais adensado e com outros estilos de vida e a construir pactos para enfrentar os desafios.

Entendemos que pensar a cidade sustentável trata-se, sim, da construção de um novo olhar do espaço urbano, de um conjunto de práticas, instrumentos e mecanismos que possam garantir, de forma contínua e consciente, respostas aos desafios constantes e complexos, mediante a apropriação da cidade pelo conjunto da sociedade.

Nesse sentido há uma correlação com a possibilidade de transformar a realidade conforme o que se deseja mudar. Assim, a utopia se refere a um movimento que procura uma transformação a partir da ação, que pode ser usado como uma orientação para a ação.

Então, a cidade sustentável é um vir a ser, não se trata da construção de uma cidade nova e nem da cidade do futuro, mas da cidade dentro de uma cidade. A cidade sustentável deve proporcionar não apenas a construção de espaços para enfrentar desafios, mas também a permanência de um debate da sociedade sobre a cidade. 
Mas o desafio, o fio condutor, está na integração entre as políticas ambientais, urbanas, sociais e econômicas, ou seja, faz-se necessário integrar políticas com foco na sustentabilidade e em prioridades que contemplem a qualidade de vida da sociedade. Isso seria pensar na durabilidade da vida humana a partir do momento em que se considera a natureza como escala de limites.

Além disso, elaboro análises a partir dos anunciados modelos de cidades, e, identificamos a partir de uma matriz elaborada pela autora, que a possível 'cidade sustentável' carrega elementos de uma cidade compacta, juntamente com os princípios da Slow City alinhados com as estratégias da Cidade Resiliente.

Em nossa investigação a respeito da sustentabilidade, julgamos necessário agregar o conceito de resiliência, pois ele introduz uma nova abordagem para se lidar com a gestão das cidades ao torná-las menos vulneráveis a partir do desenvolvimento de capacidades adaptativas a eventos adversos e ameaças naturais. Aplicado às cidades, o termo se refere à capacidade de uma cidade de gerir os problemas a fim de retornar ao estado de equilíbrio inicial.

Conforme exposto, apenas recentemente a busca da sustentabilidade se apresentou como uma alternativa possível e necessária para alcançar o objetivo de construir uma cidade ideal. Compreendemos, portanto, a sustentabilidade como um método a partir do qual é possível pensar as cidades, não sob a forma de modelos, mas como uma forma de integrar diferentes aspectos relacionados à questão urbana e de associar o urbano e o ambiental. $E$, entendemos que a sustentabilidade é um método a ser aplicado para análises, pensar e projetar as cidades.

\section{BIBLIOGRAFIA}

ACSELRAD, Henri. A duração das cidades. Sustentabilidade e risco nas políticas públicas, Rio de Janeiro: DP\&A Editora, 2001. 238 p.

CARLOS, Ana Fani Alessandri. A produção do espaço urbano - Agentes e Processos, Escalas e Desafios. São Paulo: Editora Contexto. 2014.

CHOAY, Françoise. O urbanismo: Utopias e Realidades uma antologia. 5 ed. São Paulo: Editora Perspectiva S.A., 2003. 350 p.

COMISSÃO MUNDIAL SOBRE O MEIO AMBIENTE E DESENVOLVIMENTO (CMMAD). Nosso Futuro Comum. Rio de Janeiro: Editora da Fundação Getúlio Vargas, 2 ed.1991. 430 p.

HARVEY, David. A Condição Pós-Moderna: Uma pesquisa sobre as Origens da Mudança Cultural.15 ed. São Paulo: Edições Loyola, 2006. 349 p. 
HERCULANO, Selene. Em busca da boa sociedade. Niterói: EdUFF, 2006. 426 p.

FARIAS FILHO, José Almir. Eco-urbanismo: uma revisão sobre outras formas de pensar a cidade. In ANPUR, Belo Horizonte. Anais do XVI, 2015.

LEFÈBVRE, Henri. O direito à cidade. Trad. Rubens Eduardo Frias.5 ed. São Paulo: Centauro, 2001.

LEITE, Carlos. Cidades Sustentáveis, Cidade Inteligentes: desenvolvimento sustentável num planeta urbano. Porto Alegre: Bookman, 2012.

MARICATO, Erminía. Metrópole na periferia do capitalismo: ilegalidade, desigualdade e violência. São Paulo: Hucitec, 1996. 141 p.

REZENDE, Vera Lúcia Ferreira Motta. Planejamento Urbano e Ideologia. Rio de Janeiro: Civilização Brasileira,1982. 125 p.

ROGERS, Richard. Cidades para um pequeno planeta. 2ª ed. São Paulo: Saraiva, 2016.

SACHS, Ignacy. Desenvolvimento includente, sustentável, sustentado. Rio de Janeiro: Garamond Universitária, 2004. 237

SANTOS, Milton. A Natureza do Espaço: Técnica e Tempo, Razão e Emoção.4. ed. 2. reimpr. São Paulo: Editora da Universidade de São Paulo, 2006.

SECCHI, Bernard. Primeira Lição do Urbanismo. São Paulo. Editora Perspectiva SA, 2006

UNISDR. Como Construir Cidades Mais Resilientes: Um Guia para Gestores Públicos Locais. Uma contribuição à Campanha Global 2010-2015 Construindo Cidades Resilientes - Minha Cidade está se preparando! Genebra, 2012.

VEIGA, José Eli da. Desenvolvimento sustentável: o desafio do século XXI. Rio de Janeiro: Garamond, 2010. 238 